\title{
Investigating the Role of Ligand Electronics on Stabilizing Electrocatalytically Relevant Low-Valent Co(I) Intermediates
}

\author{
David P. Hickey, ${ }^{\dagger}$ Christopher Sandford, ${ }^{\dagger}$ Zayn Rhodes, Tobias Gensch, Lydia R. Fries, \\ Matthew S. Sigman, ${ }^{*}$ a and Shelley D. Minteer*i)
}

Department of Chemistry, University of Utah, 315 South 1400 East, Salt Lake City, Utah 84112, United States

\section{Supporting Information}

\begin{abstract}
Cobalt complexes have shown great promise as electrocatalysts in applications ranging from hydrogen evolution to $\mathrm{C}-\mathrm{H}$ functionalization. However, the use of such complexes often requires polydentate, bulky ligands to stabilize the catalytically active $\mathrm{Co}(\mathrm{I})$ oxidation state from deleterious disproportionation reactions to enable the desired reactivity. Herein, we describe the use of bidentate electronically asymmetric ligands as an alternative approach to stabilizing transient $\mathrm{Co}(\mathrm{I})$ species. Using disproportionation rates of electrochemically generated $\mathrm{Co}(\mathrm{I})$ complexes as a model for stability, we measured the relative stability of complexes prepared with a series of $\mathrm{N}, \mathrm{N}$-bidentate ligands. While the stability of $\mathrm{Co}(\mathrm{I}) \mathrm{Cl}$ complexes demonstrates a correlation with experimentally measured thermodynamic properties, consistent with an outer-sphere electron transfer
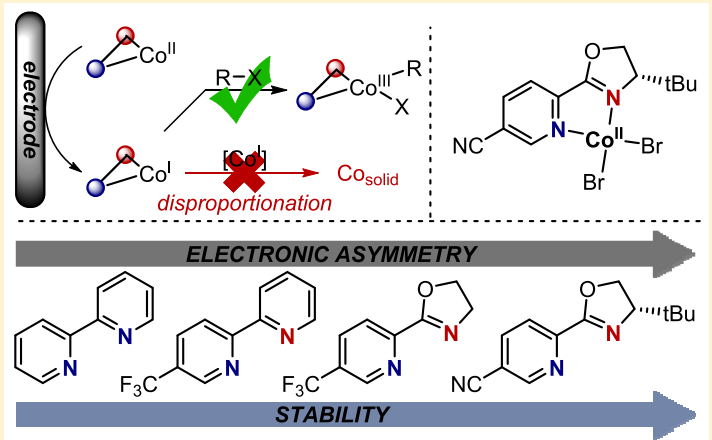
process, the set of ligated $\mathrm{Co}(\mathrm{I}) \mathrm{Br}$ complexes evaluated was found to be preferentially stabilized by electronically asymmetric ligands, demonstrating an alternative disproportionation mechanism. These results allow a greater understanding of the fundamental processes involved in the disproportionation of organometallic complexes and have allowed the identification of cobalt complexes that show promise for the development of novel electrocatalytic reactions.
\end{abstract}

\section{INTRODUCTION}

Complexes of first-row transition metals have a longestablished utility in the area of homogeneous electrochemical catalysis. In particular, cobalt(II) compounds ${ }^{1}$ have proven especially useful in several catalytic reactions ranging from hydrogen evolution ${ }^{2}$ to $\mathrm{C}-\mathrm{H}$ functionalization ${ }^{3}$ to $\mathrm{C}\left(\mathrm{sp}^{2}\right)-$ $\mathrm{C}\left(\mathrm{sp}^{2}\right)$ cross-coupling. ${ }^{4}$ The versatility of $\mathrm{Co}(\mathrm{II})$ complexes in electrocatalysis can be attributed to the reactive nature of their corresponding electrochemically generated $\mathrm{Co}(\mathrm{I})$ intermediates. ${ }^{5}$ However, since these $\mathrm{Co}(\mathrm{I})$ intermediates are highly reactive, they are prone to a multitude of decomposition pathways.

As extensively reported by Buriez, ${ }^{6}$ the predominant decomposition pathway of electrochemically generated $\mathrm{Co}(\mathrm{I})$ species proceeds via disproportionation to $\mathrm{Co}$ (II) and $\mathrm{Co}(0)$, which subsequently results in precipitation of metallic $\mathrm{Co}(0)$, removing cobalt from the electrocatalytic cycle (Scheme 1). To circumvent these deleterious pathways, cobalt electrocatalysts have been traditionally stabilized ${ }^{7}$ through polydentate ligands such as cobalamin derivatives ${ }^{8}$ and salen complexes. ${ }^{9}$ Oxidative addition of these stabilized $\mathrm{Co}(\mathrm{I})$ intermediates into alkyl halides affords alkyl cobalt species, which undergo subsequent homolytic cleavage of the $\mathrm{Co}-\mathrm{C}$ bond (e.g., often by the absorption of light or proton-coupled electron transfer $\left.{ }^{10}\right)$ to form nucleophilic alkyl radical species. ${ }^{11}$ Additionally, outersphere electron transfer from low oxidation states of cobalt has
Scheme 1. Disproportionation of Electrochemically Generated Co(I) Species

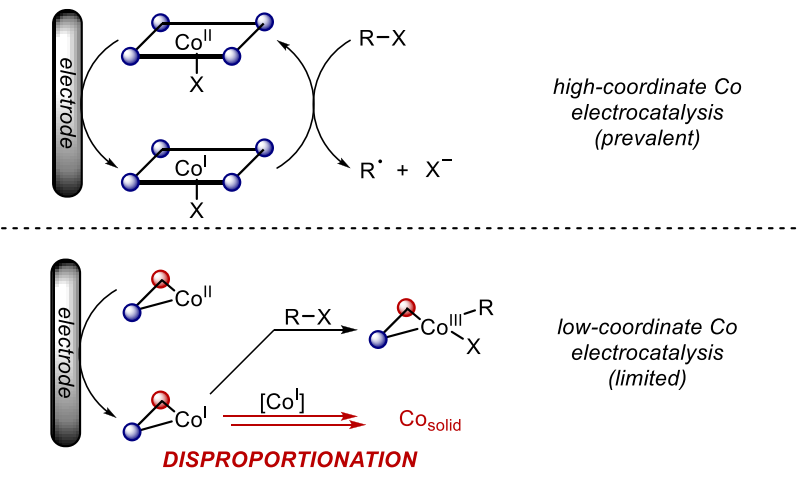

been shown to produce alkyl radicals without formation of Co-C bonds. ${ }^{12}$

In order to expand the utility of cobalt electrocatalysts in synthetic transformations, low-dentate ligands would provide additional free coordination sites for binding to organic substrates, facilitating other key organometallic steps (transmetalation, migratory insertion, and/or reductive elimination). However, these low-dentate ligands would need to stabilize the

Received: November 25, 2018

Published: January 1, 2019 
$\mathrm{Co}(\mathrm{I})$ intermediate such that oxidative addition outcompetes destructive disproportionation. Additionally, incorporating chiral ligands would allow for the possibility of enantioselective catalysis, which remains challenging for cobalt electrocatalysts that act as sources of transient carbon-centered radicals in solution. $^{13}$

On the basis of this principle, we aimed to identify electronic and steric properties for a range of $\mathrm{N}, \mathrm{N}$-bidentate ligands that impact the disproportionation rates of electrochemically generated $\mathrm{Co}(\mathrm{I})$ intermediates. Herein, we report the enhanced stabilization provided by electronically asymmetric pyridyl oxazoline (pyrox) over bipyridine (bpy) ligands for $[\mathrm{LCo}(\mathrm{I})(\mathrm{MeCN}) \mathrm{Br}]$ complexes. In contrast, the comparable $[\mathrm{LCo}(\mathrm{I})(\mathrm{MeCN}) \mathrm{Cl}]$ complexes show alternative trends based on the electronic properties of the ligands. By correlation of experimental properties as well as computational parametrization of the ligands, we are able to probe the distinction between the disproportionation mechanisms according to the halide of the complex.

\section{RESULTS AND DISCUSSION}

2.1. Determination of Ligation State. To initiate our investigation, an extensive ligand set was compiled of $\mathrm{N}, \mathrm{N}$ bidentate ligands with various substitution patterns to represent a gradient of electronic and steric effects. Complexes $^{14}$ were generated in situ by mixing $\mathrm{CoBr}_{2}$ in acetonitrile with the desired ligand under anhydrous conditions and an Ar atmosphere. Since our goal was to determine disproportionation rates under conditions that mimic a catalytic environment, we first sought to ensure that monoligated complexes were the predominant species in solution. In order to ascertain ligation states and reduction potentials of the cobalt complexes, voltammetric titration experiments were conducted, in which increasing concentration of ligand was added to a solution of $\mathrm{Co}$ (II), while the ratio of peak currents corresponding to $\mathrm{Co}$ (II) complexes for each ligation state was monitored by square wave voltammetry.

Square wave voltammograms (SWVs) were obtained from solutions of $1 \mathrm{mM} \mathrm{CoBr} 2$ after sequential additions of ligand. As a representative example, the SWV for $\mathrm{CoBr}_{2}$ titrated with unsubstituted 2,2'-bipyridine (L1) reveals two distinct redox species (Figure 1A). The first appears at $E_{1 / 2}=-1.43 \mathrm{~V}$ (vs $\mathrm{Fc} / \mathrm{Fc}^{+}$) after addition of 0.5 equiv of $\mathrm{L} 1$, while the second appears at $E_{1 / 2}=-1.34 \mathrm{~V}$ and arises after $>1.5$ equiv of $\mathbf{L} 1$ was added. These redox features were attributed to the $\mathrm{Co}(\mathrm{II}) /$ $\mathrm{Co}(\mathrm{I})$ couple for mono- and bisligated $\mathrm{Co}(\mathrm{II})\left(\mathrm{LCoBr}_{2}\right.$ and $\mathrm{L}_{2} \mathrm{CoBr}_{2}$ ), respectively. The peak heights were normalized to the corresponding diffusion coefficients (as determined by cyclic voltammetry) and plotted as a function of relative ligand concentration to generate an approximate concentration profile for each ligation state (Figure 1B). By performing this titration for all ligands studied, we were able to select Co:L ratios to maximize the relative concentration of monoligated species in solution.

2.2. Electrochemical Analysis of Disproportionation Rates for [LCo(I)(MeCN)Br] Complexes. With the relative concentration of ligation states determined, cyclic voltammetry (CV) was employed to study the rate of disproportionation in a method similar to that described by Buriez et al. (Figure 2). ${ }^{6 \mathrm{~b}}$ From the Randles-Sevcik equation, the peak cathodic current $\left(i_{\mathrm{pc}}\right)$ and the peak anodic current $\left(i_{\mathrm{pa}}\right)$ for a $\mathrm{CV}$ of a $\mathrm{Co}(\mathrm{II})$ complex are proportional to the concentration of $\mathrm{Co}$ (II) and $\mathrm{Co}(\mathrm{I})$ at the electrode interface. For a purely reversible
A.

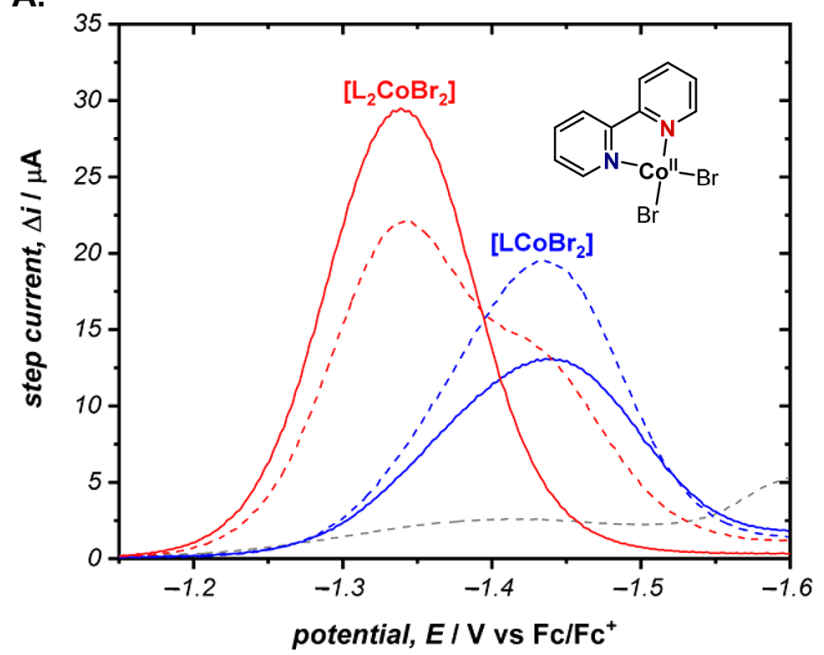

B.

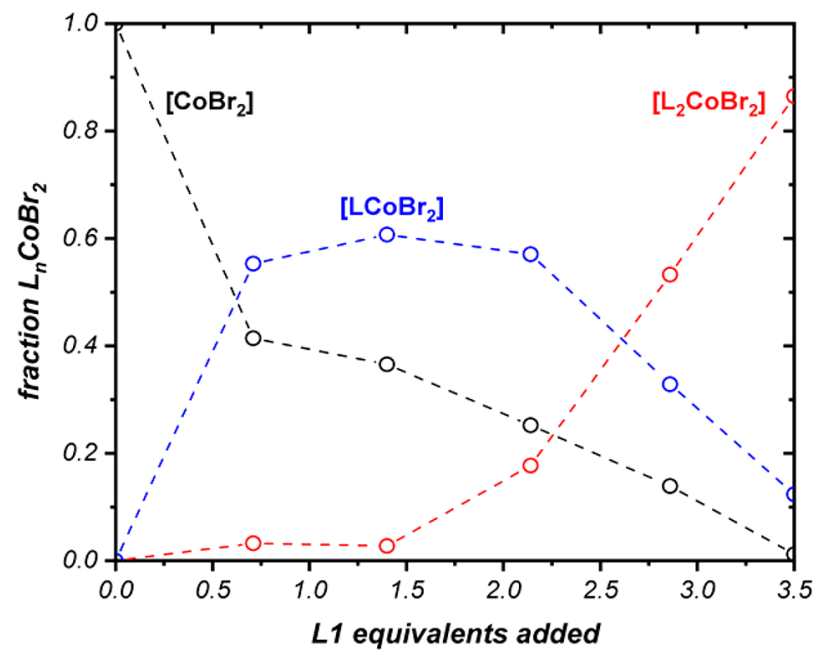

Figure 1. (A) Square wave voltammograms of $1.0 \mathrm{mM} \mathrm{CoBr} 2$ in the

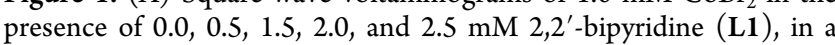
$100 \mathrm{mM}$ solution of $\mathrm{Bu}_{4} \mathrm{NPF}_{6}$ in acetonitrile. (B) Voltammetric titration of $\mathrm{CoBr}_{2}$ in the presence of $\mathbf{L} \mathbf{1}$ resulting from square wave voltammograms. Voltammograms were performed with a $3 \mathrm{~mm}$ boron-doped diamond working electrode at $50 \mathrm{~Hz}$ under an $\mathrm{Ar}$ atmosphere at $25^{\circ} \mathrm{C}$.

electrochemical process, we would expect that the ratio of $i_{\mathrm{pa}} /$ $i_{\mathrm{pc}} \approx 1$. However, if the electrochemically generated $\mathrm{Co}(\mathrm{I})$ undergoes a chemical reaction prior to being electrochemically reoxidized then $i_{\mathrm{pa}} / i_{\mathrm{pc}}<1$. Therefore, by plotting $i_{\mathrm{pa}} / i_{\mathrm{pc}}$ versus the amount of time elapsed between peak currents, we can rapidly monitor rates of the intervening chemical process.

On the basis of this method, CVs were performed at variable scan rates (ranging from $1 \mathrm{mV} \mathrm{s}^{-1}$ to $6 \mathrm{~V} \mathrm{~s}^{-1}$ ) across an electrochemical window limited to the $\mathrm{Co}(\mathrm{II}) / \mathrm{Co}(\mathrm{I})$ redox couple (Figure $2 \mathrm{C}$ ). Comparing the value of the $[\mathrm{Co}(\mathrm{I})]_{t}$, calculated by the ratio $i_{\mathrm{pa}} / i_{\mathrm{pc}}$, with the time taken to scan between the peak cathodic and the anodic potentials (according to the scan rate) allows determination of the reaction rate. A plot of $1 /[\mathrm{Co}(\mathrm{I})]_{t}$ against time is a straight line as the disproportionation is a second-order process with the gradient equal to the rate constant (Figure 2D). An alternative method $^{6 \mathrm{~b}}$ for determining the rate constant by measuring the half-life from a sigmoidal curve formulated by plotting $i_{\mathrm{pa}} / i_{\mathrm{pc}}$ vs the natural log of the scan rate is described in the Supporting 
A.

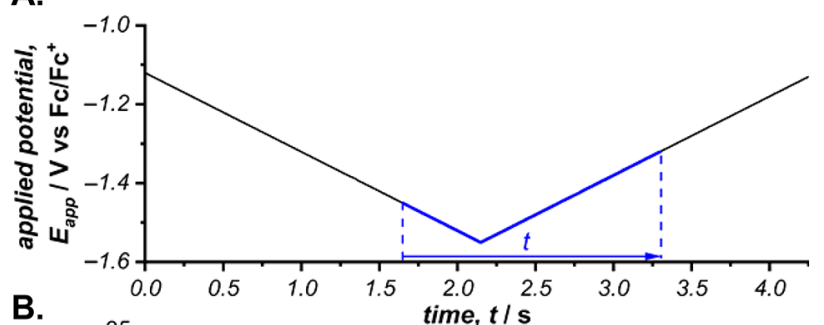

B.

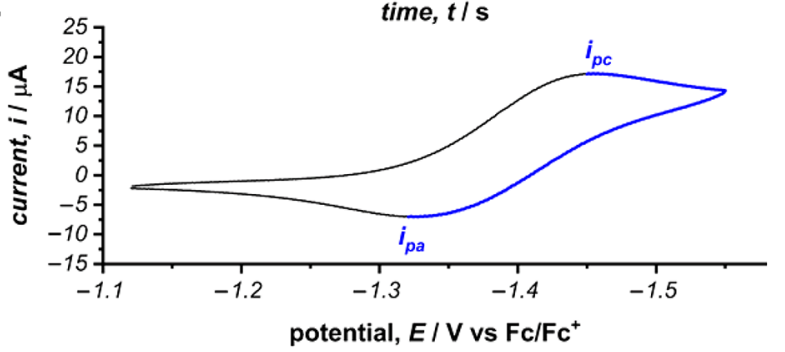

C.

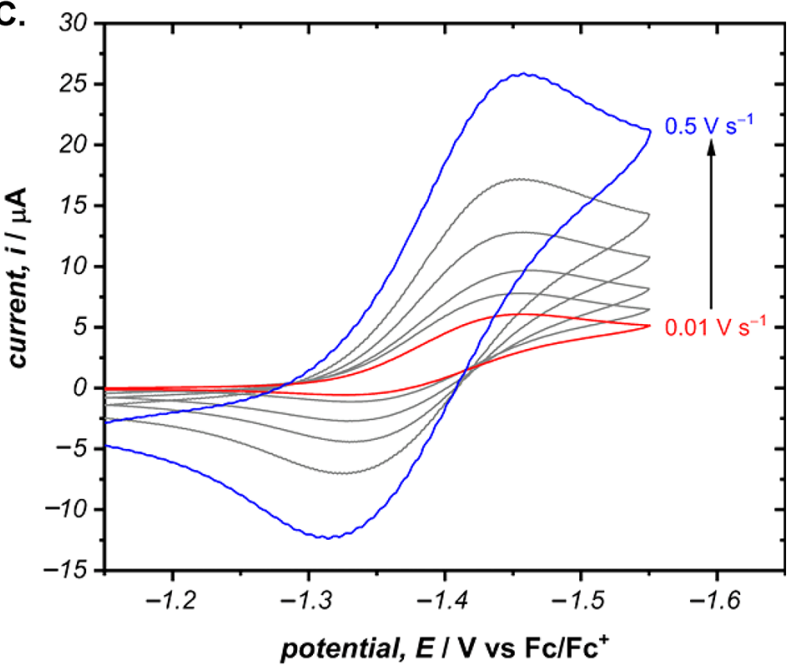

D.

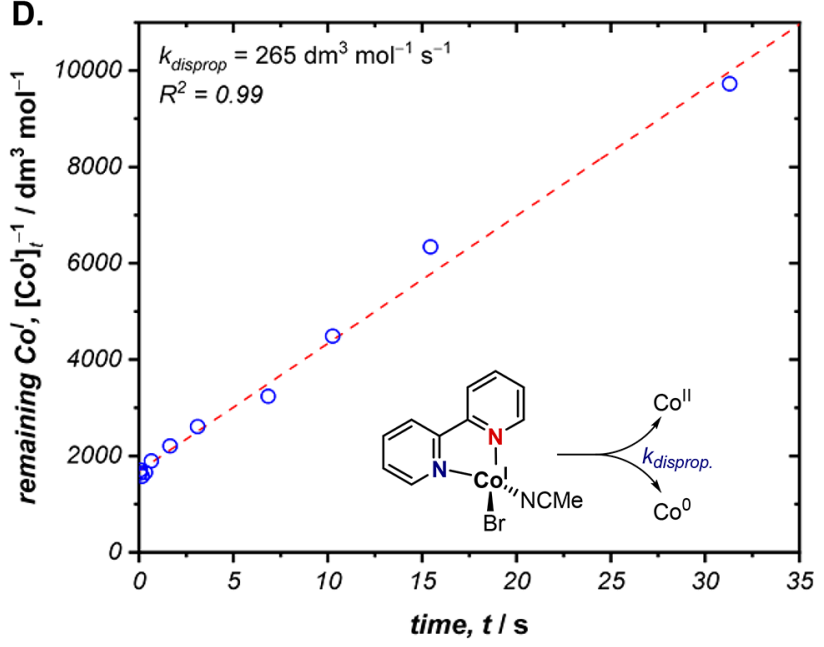

Figure 2. (A) Potential waveform and (B) example cyclic voltammogram $(\mathrm{CV})$ used to determine the concentration of $\mathrm{Co}(\mathrm{I})$ remaining after the time taken to scan between the peak cathodic and anodic currents on a CV. (C) CVs of $1.0 \mathrm{mM} \mathrm{CoBr}_{2}$ in the presence of 1.0 $\mathrm{mM} \mathrm{L1}$ at varying scan rates in a $100 \mathrm{mM}$ solution of $\mathrm{Bu}_{4} \mathrm{NPF}_{6}$ in acetonitrile. CVs are plotted in polarographic notation with positive currents corresponding to reduction. (D) Graph depicting the determination of the disproportionation rate constant (gradient) by plotting the inverse $\mathrm{Co}(\mathrm{I})$ concentration against time for $1.0 \mathrm{mM}$ $\mathrm{CoBr}_{2}$ in the presence of $1.0 \mathrm{mM} \mathrm{L1}$.
Information. Both methods resulted in nearly identical rate constants for all ligands studied, but the numbers cited below were obtained by the method depicted in Figure 2D.

Following this technique, we determined the rate constant for disproportionation of $\mathrm{Co}(\mathrm{I})$ ligated by an extensive range of $N, N$-ligands, including a variety of electronically and/or sterically differentiated bipyridine, phenanthroline, pyrox, and quinox ligands, which are common bidentate ligands in oxidative processes (Figure 3).

Measuring the rate constant using CVs in this manner allowed us to obtain data spanning over 4 orders of magnitude, although the rate constant for some additional ligands could not be obtained where the $\mathrm{CV}$ was completely irreversible up to scan rates of $10 \mathrm{~V} \mathrm{~s}^{-1}\left(k>50000 \mathrm{dm}^{3} \mathrm{~mol}^{-1} \mathrm{~s}^{-1}\right.$ for $4,4^{\prime}$ dimethoxybipyridine and bioxazoline [Biox] ligands). Additionally, it should be noted that this technique can be used to rapidly assimilate kinetic data for transient intermediates, with the typical rate constant obtained within only $4 \mathrm{~h}$ of experimentation.

Comparing the data trends in Figure 3, one can observe that the pyrox ligand class generally affords greater stability than bpy ligands (see, for example, that the most stable bpy ligand is L19). For the pyrox ligand class, it was found that the addition of electron-withdrawing ligands on to the pyridine ring has the most significant effect in stabilizing the $\mathrm{Co}(\mathrm{I})$ intermediate (e.g., addition of a 5-trifluoromethyl group onto the pyridine of the unsubstituted pyrox decreases the rate constant by a factor of 35, comparing L7 with L25). The same general trend in increasing stabilization by the addition of electron-withdrawing groups can be observed within the bpy ligand class (comparing L1 and L10), despite some subtleties that will be discussed in more detail in section 2.3.

Concerning steric constraints introduced by the ligand close to the metal center of the complex (on the pyridine ring of pyrox comparing $\mathbf{L} 7$ and $\mathbf{L 8}$, on the oxazoline comparing $\mathbf{L 2 5}$ and L27), it appears from this data set that substituent size has a more modest impact than electronics. This feature could be advantageous in asymmetric catalysis with pyrox ligands, where changing the steric properties could allow optimization of enantioinduction, ${ }^{15}$ while not impacting the disproportionation event and altering catalyst decomposition during the course of the reaction.

2.3. Effect of Halide on Disproportionation Rate. As a consequence of the electronic effects of ligation on the stability of $[\mathrm{LCo}(\mathrm{I})(\mathrm{MeCN}) \mathrm{Br}]$ complexes, we next considered the impact of the halide on the disproportionation event: not only could the halide change the electronic properties of the complex but also relative stabilities of the LCo(I)X complexes would inform the choice of alkyl-halide species utilized for downstream oxidative addition processes in catalysis. A subset of 13 ligands was selected to span the range of stability of the bromide complexes, and the disproportionation rate constant for the chlorides was measured by the same process as described above. Comparing the data collected for the two differing sets of halide complexes showcases two significant differences (Figure 4): first, the range of free energies of activation $\left(\Delta G^{\sharp}\right)$ is smaller for the chloride complexes, suggesting that the ligand has less impact on the disproportionation event; second, while the bromide complexes are most stabilizated by pyrox ligands (L25-L34), it was found that highly electron-deficient bipyridine ligands (L10 and L13) provide the greatest stability for the chloride complexes. 
<smiles>Cc1ccnc(-c2cc(C)ccn2)c1</smiles>

L2: 26100

(94 ms)<smiles>Cc1cccc(C2=NCCO2)n1</smiles>

L8: 214<smiles>Cc1ccnc(-c2cc(C(F)(F)F)ccn2)c1</smiles>

L15: 47.5<smiles>FC(F)(F)c1ccc(C2=NCCO2)nc1</smiles>

L22: 28.2 iPr<smiles>FC(F)(F)c1ccc(C2=NCCO2)nc1</smiles>

L29: $8.73 \mathrm{Me}$<smiles>Cc1ccnc(-c2ccccn2)c1</smiles>

L3: 5650<smiles>Cc1cccc(-c2cccc(C(F)(F)F)n2)n1</smiles>

L9: 140<smiles>Cc1ccc2ccc3ccc(C)nc3c2n1</smiles>

L16: 40.6<smiles>CC1(C)CN=C(c2ccc3ccccc3n2)O1</smiles>

L23: 27.9 iPr<smiles>FC(F)(F)c1ccc(C2=NCCO2)nc1</smiles>

L30: 6.86 Bn<smiles>Cc1ccnc(C2=NCCO2)c1</smiles>

L4: 2800<smiles>CC(C)(C)c1ccnc(-c2cc(C(C)(C)C)ccn2)c1</smiles>

L5: 2670<smiles>Fc1cc(F)c(C2=NC(P)CO2)c(F)c1</smiles>

L10: 105<smiles>c1cnc2c(c1)ccc1cccnc12</smiles>

L6: 850<smiles>c1ccc(C2=NCCO2)nc1</smiles>

L7: 574 (2.6 s)<smiles>N#Cc1ccc(-c2ccc(C#N)cn2)nc1</smiles>

L13: 64.1<smiles>Cc1cccc(-c2ccccn2)n1</smiles><smiles>FC(F)(F)c1ccc(-c2ccccn2)nc1</smiles><smiles>FC(F)(F)c1cccc(C2=NCCO2)n1</smiles>

L20: 33.9 "tBu

L19: 35.3<smiles>c1ccc(-c2ccccn2)nc1</smiles>

L1: 265

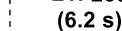<smiles>FC(F)(F)c1ccc(C2=NC3C=CC(CC3)O2)nc1</smiles>

L14: 52.6<smiles>c1ccc2nc(C3=NCCO3)ccc2c1</smiles>

L21: 30.4 "tBu

L17: 40.4

L18: 36.7<smiles>FC(F)(F)c1ccnc(C2=NCCO2)c1</smiles><smiles>FC(F)(F)c1ccc(C2=NCCO2)nc1</smiles>

L24: 18.7 tBu

L25: 16.1

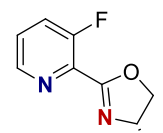<smiles>CC1(C)CN=C(c2ccc(C(F)(F)F)cn2)O1</smiles>

L31: 4.87 " $\mathrm{tBu}$<smiles>Cc1cc2ccccc2nc1C1=NCCO1</smiles>

$\mathrm{F}_{3} \mathrm{C}$<smiles>c1ccc(C2=NCCO2)nc1</smiles>

L26: 14.8 iPr<smiles>CC1(C)CN=C(c2ccc(C#N)cn2)O1</smiles>

L33: 1.79 iPr
L27: 13.1 "tBu (101 s)

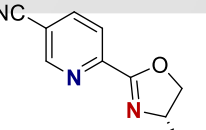

L34: 1.63 tBu $(\mathbf{8 4 7} \mathrm{s})$

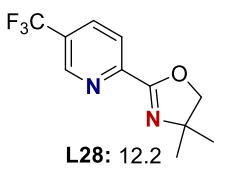

\begin{tabular}{|l|}
\hline Ligands ordered \\
according to \\
decreasing \\
disproportionation \\
rate constant \\
L: $\boldsymbol{k}_{\text {disprop }}\left(t_{1 / 2}\right)$
\end{tabular}

Figure 3. Rate constants (units $\mathrm{dm}^{3} \mathrm{~mol}^{-1} \mathrm{~s}^{-1}$ ) for the disproportionation of monoligated $[\mathrm{LCo}(\mathrm{I})(\mathrm{MeCN}) \mathrm{Br}$ ] complexes containing the ligands displayed; half-lives of selected complexes included in parentheses. Measurements made utilizing $1.0 \mathrm{mM} \mathrm{CoBr}_{2}$ in the presence of 1.0 equiv of ligand (unless otherwise noted in the Supporting Information) in a $100 \mathrm{mM}$ solution of $\mathrm{Bu}_{4} \mathrm{NPF}_{6}$ in acetonitrile. Arrow signifies direction of decreasing disproportionation rate constant.

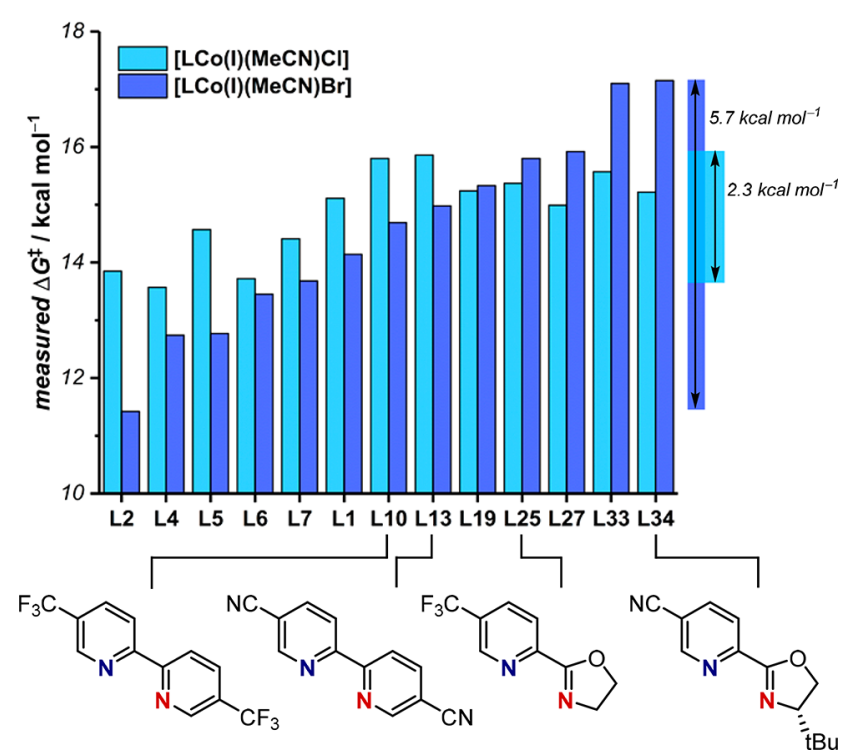

Figure 4. Comparison of the free energy of activation for disproportionation of monoligated $[\mathrm{LCo}(\mathrm{I})(\mathrm{MeCN}) \mathrm{Cl}]$ and $[\mathrm{LCo}-$ (I) $(\mathrm{MeCN}) \mathrm{Br}]$ complexes. For ligand structures not displayed, see Figure 3.

To examine the differing effects of ligand properties on the two sets of halide complexes, we were interested in the trends of sequentially adding electron-withdrawing trifluoromethyl groups at the $5 / 5^{\prime}$ positions of bipyridine (Figure 5 ). For the chloride complexes, incorporating additional trifluoromethyl

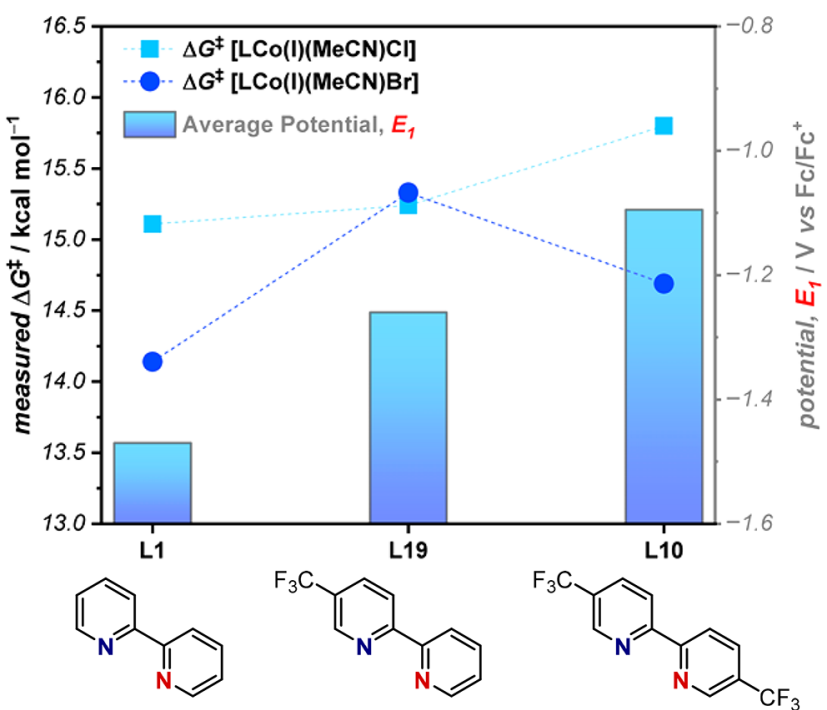

Figure 5. Comparison of the trend between sequentially more electron-withdrawing bpy ligands with the free energy of activation for disproportionation of $[\mathrm{LCo}(\mathrm{I})(\mathrm{MeCN}) \mathrm{Cl}]$ and $[\mathrm{LCo}(\mathrm{I})(\mathrm{MeCN}) \mathrm{Br}]$, and effect on the potential of the $\mathrm{Co}(\mathrm{II}) / \mathrm{Co}(\mathrm{I})$ couple, $E_{1}$. Average potential for the bromide and chloride complexes is displayed for graphical simplicity. Individual potentials of $\mathrm{Cl}$ and $\mathrm{Br}$ complexes are within $70 \mathrm{mV}$ of one another.

groups sequentially kinetically stabilizes the complex, which is consistent with the thermodynamic nature of the $\mathrm{Co}(\mathrm{II}) /$ $\mathrm{Co}(\mathrm{I})$ reduction potential $\left(E_{1}\right)$ becoming sequentially less 
negative. In contrast, the $[\mathrm{LCo}(\mathrm{I})(\mathrm{MeCN}) \mathrm{Br}]$ set is most stabilized by the mono-5-(trifluoromethyl)bipyridine ligand L19, demonstrating the kinetic advantage to employing an $\mathrm{N}, \mathrm{N}$-bidentate ligand with electronically differentiated nitrogen donors. This trend matches the greater kinetic stability of the pyrox $[\mathrm{LCo}(\mathrm{I})(\mathrm{MeCN}) \mathrm{Br}]$ complexes, in which the difference between the two nitrogen donors is further enhanced.

Of additional note is that the most stable $[\mathrm{LCo}(\mathrm{I})(\mathrm{MeCN})$ $\mathrm{Cl}$ ] complex investigated (with L13) has a half-life of approximately $2 \mathrm{~min}$ and is significantly less stable than the pyrox-ligated bromide complexes (half-life of $>14$ min with L34). While a number of $\mathrm{CoI}_{2}$ complexes were also explored, the complexity of the SWVs points to the existence of dimeric species in solution (vide infra, and see Supporting Information), and hence, a full comparison of disproportionation rates cannot be made.

2.4. Correlation between Experimentally Derived Thermodynamic Properties and Disproportionation Rates. In order to examine the origin(s) of the different trends in kinetic stability for the bromide and chloride complexes, we sought to identify computationally and/or experimentally derived structural descriptors for each of the ligands under investigation that correlate to the experimentally determined rate of disproportionation. Our preliminary expectation was that the rate of disproportionation would correlate directly with the thermodynamic redox potential $\left(E_{1 / 2}\right.$ corresponding to the $\mathrm{Co}(\mathrm{II}) / \mathrm{Co}(\mathrm{I})$ couple, $\left.E_{1}\right){ }^{16}$ Indeed, analysis of the $[\mathrm{LCo}(\mathrm{I})(\mathrm{MeCN}) \mathrm{Cl}]$ data set demonstrates a correlation between $E_{1}$ and $\Delta G^{\ddagger}$ (Figure $6 \mathrm{~A})$. This correlation is a manifestation of the enhanced stability afforded to a $\mathrm{Co}(\mathrm{I})$ complex when it is thermodynamically more challenging to oxidize to $\mathrm{Co}(\mathrm{II})$.

Since the disproportionation event also involves concomitant reduction of a second complex from $\mathrm{Co}(\mathrm{I})$ to $\mathrm{Co}(0)$, the thermodynamic feasibility of this transform can be added to the initial model to provide a statistically more robust bivariate model (Figure 6B). These results display how the kinetics of the $[\mathrm{LCo}(\mathrm{I})(\mathrm{MeCN}) \mathrm{Cl}]$ disproportionation event is determined by thermodynamics. This suggests that the corresponding activation energies for electron transfer are small, which is consistent with an outer-sphere electron transfer process between two $\mathrm{Co}(\mathrm{I})$ complexes in which reorganization precedes electron transfer, such that the transition state resembles the products. 16,17

In contrast, a poor correlation is found between free energies of activation and thermodynamic redox potentials for the $[\mathrm{LCo}(\mathrm{I})(\mathrm{MeCN}) \mathrm{Br}]$ data set (Figure $6 \mathrm{C}$ ). While the same general trend in greater kinetic stability for a complex with a less negative $\mathrm{Co}(\mathrm{II}) / \mathrm{Co}(\mathrm{I})$ redox couple is observed, additional factors must be influencing the disproportionation rate, suggesting that the bromide complexes operate through an alternative disproportionation mechanism.

2.5. Correlation between Computationally Derived Ligand Properties and Disproportionation Rates for Chloride Complexes. To investigate the disparity between the mechanisms for the two halides, we next opted to use computational methods to parameterize structural features of the ligands and/or complexes. ${ }^{18}$ In the first instance, we interrogated possible properties of the free ligands that influence the thermodynamically controlled disproportionation of the chloride complexes. Utilizing parameters derived from the free ligands in their ground states, a strong bivariate correlation (Figure 7A) was found with the partial charge on
A.

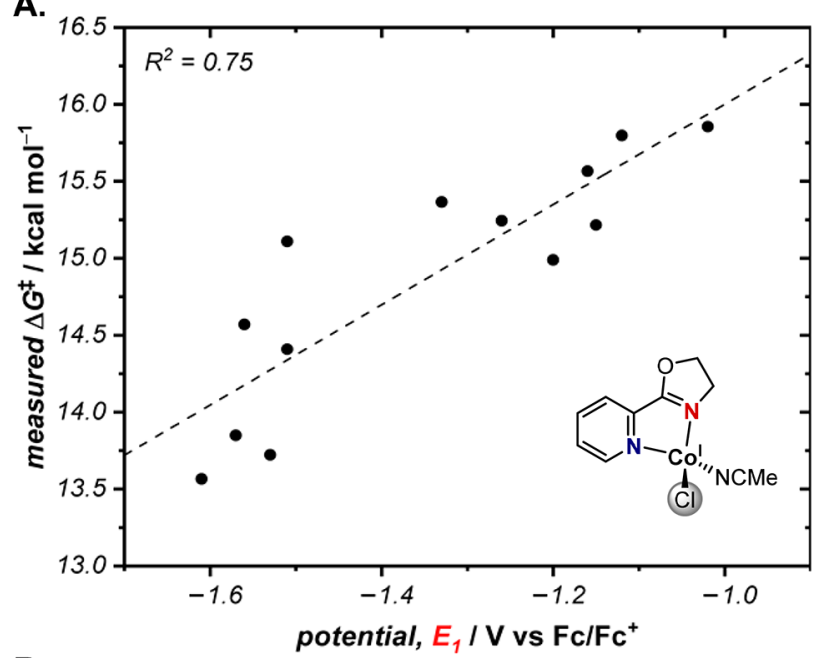

B.
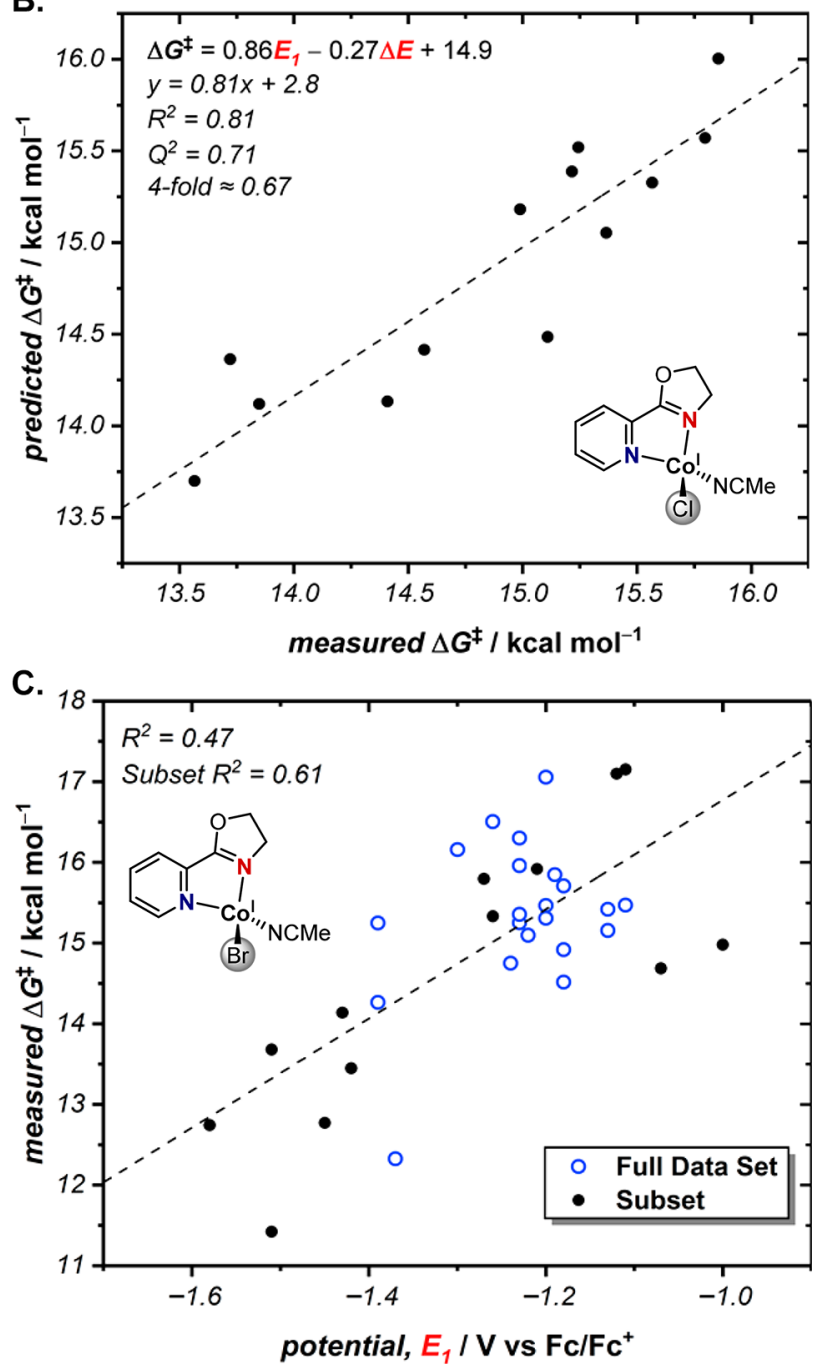

Figure 6. (A) Correlation of $\Delta G^{\ddagger}$ for $[\mathrm{LCo}(\mathrm{I})(\mathrm{MeCN}) \mathrm{Cl}]$ with the $\mathrm{Co}(\mathrm{II}) / \mathrm{Co}(\mathrm{I})$ couple reduction potential, $E_{1}$. (B) Addition of the $\mathrm{Co}(\mathrm{I}) / \mathrm{Co}(0)$ reduction couple $\left(E_{2}\right)$ to the model $\left(\Delta E=E_{1}-E_{2}\right)$. (C) Comparison with the correlation shown in Figure $6 \mathrm{~A}$ for the full $[\mathrm{LCo}(\mathrm{I})(\mathrm{MeCN}) \mathrm{Br}]$ data set (the same subset of ligands used with the chlorides is displayed as black circles; full data set as hollow blue circles plus subset. For comparison with Figure 6B, see Supporting Information). 
A.

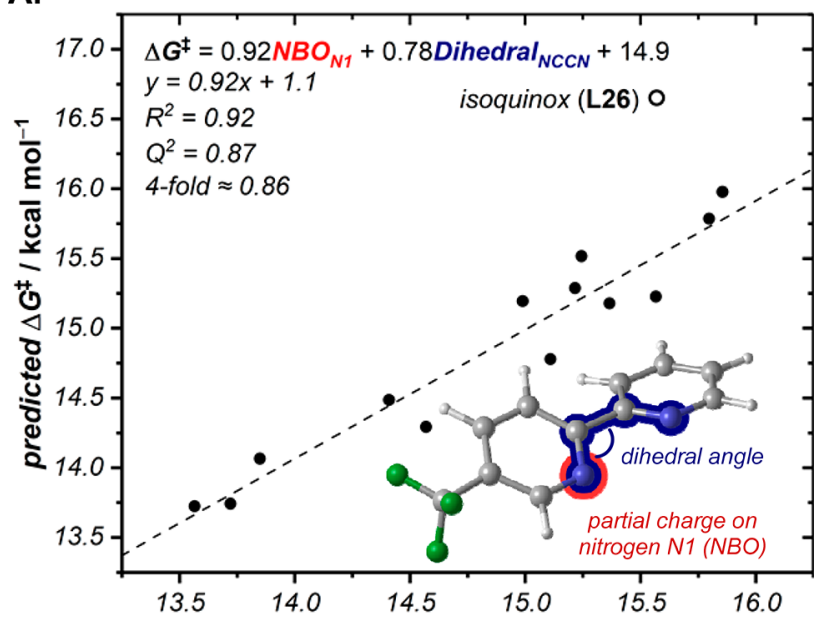

B.
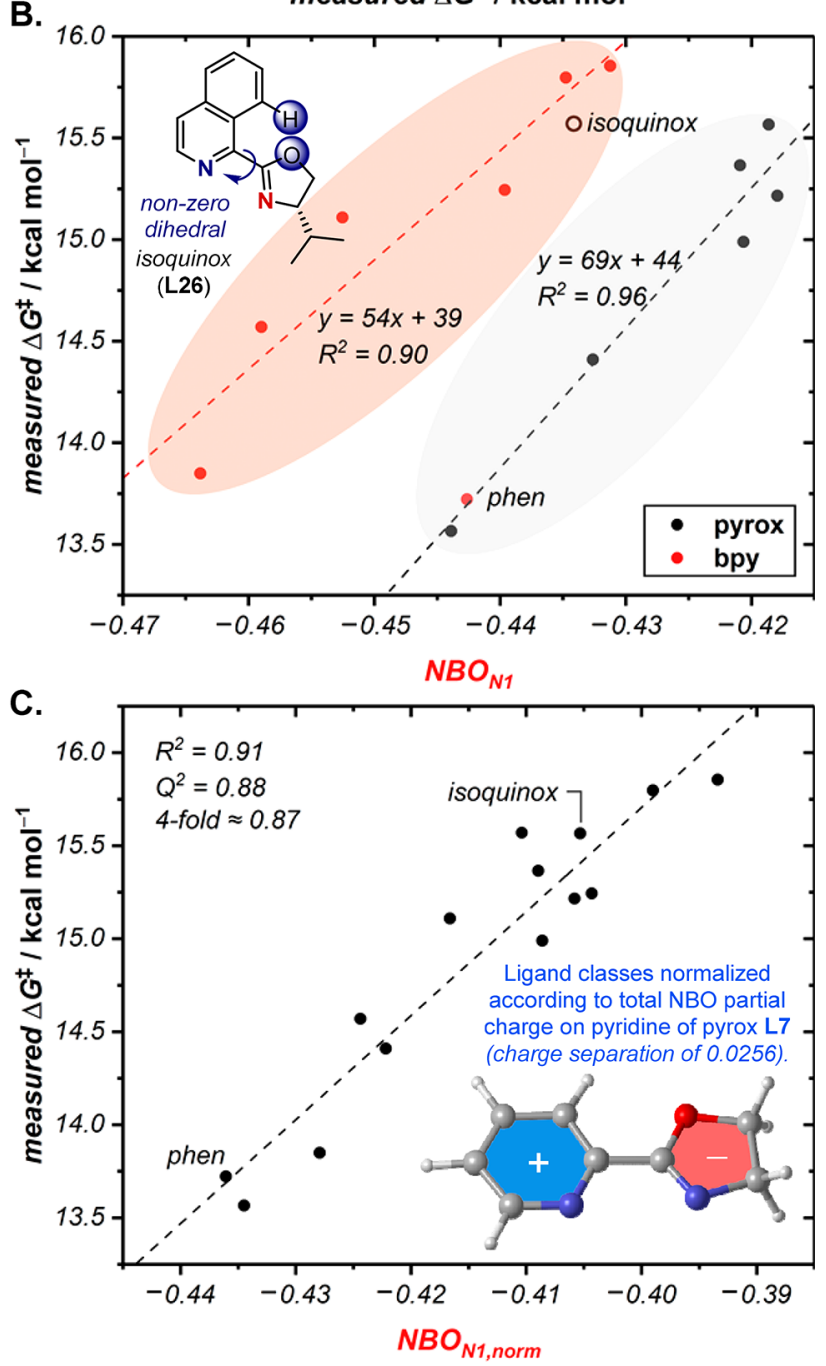

Figure 7. (A) Correlation of $\Delta G^{\ddagger}$ for $[\mathrm{LCo}(\mathrm{I})(\mathrm{MeCN}) \mathrm{Cl}]$ with the partial charge on the most electron-deficient nitrogen (defined as $\mathrm{N} 1$ ) based on NBO, and dihedral angle of the ligand in the ground state. (B) Two distinct correlations with $\mathrm{NBO}_{\mathrm{N} 1}$ observed according to dihedral angle (phen included in correlation statistics of pyrox class). (C) Correlation of $\Delta G^{\ddagger}$ with the normalized partial charge according to NBO calculated using the geometry of the ligand in the $[\mathrm{LCo}(\mathrm{I})(\mathrm{MeCN}) \mathrm{Cl}]$ complex $\left(\mathrm{NBO}_{\mathrm{N} 1, \text { norm }}\right)$. Isoquinox ligand $\mathbf{L 2 6}$ is included in correlation statistics for Figure $7 \mathrm{C}$ only. the most electron-deficient nitrogen based on natural bond orbitals $\left(\mathrm{NBO}_{\mathrm{N} 1}\right)$ and the dihedral angle between the two rings (NCCN dihedral). Separating the two parameters, $\mathrm{NBO}_{\mathrm{N} 1}$ measures the degree of destabilization of $\mathrm{Co}(\mathrm{I})$ from additional electron donation from an electron-rich ligand to $\mathrm{Co}$, facilitating easier oxidation to $\mathrm{Co}(\mathrm{II})$, but the significance of the dihedral angle was not immediately obvious.

When the univariate correlation with only $\mathrm{NBO}_{\mathrm{N} 1}$ was plotted, two distinct sets of data were observed (Figure 7B), corresponding to the bpy and pyrox ligand classes. Interestingly, the phenanthroline ligand appears to fit the pyrox correlation, even though it may be intuitively predicted to be part of the bipyridine class. Indeed, the conjugated phenanthroline ring systems lock the conformation with a ring dihedral angle of zero, while the bipyridine ligands twist to minimize sterics in the ground state to give a nonzero (29$32^{\circ}$ ) ring dihedral angle. In contrast, when the bipyridines bind to cobalt, the energetic stabilization of placing the two nitrogen lone pairs in a plane with the metal overcomes the steric strain and reduces the dihedral angle to nearly zero. For the pyrox ligands, the smaller five-membered ring (without a hydrogen at the $3^{\prime}$ position as in bpy ligands) has less steric interactions than for bipyridines, and thus, the dihedral angle is approximately zero in both the ground state ligand and the resulting cobalt complex. Thus, we propose that in the model shown in Figure 7A the dihedral angle serves to describe the change in geometry and, consequently, the partial charge on nitrogen upon complexation of the ligand. The binary effect of the dihedral angle in Figure $7 \mathrm{~A}$ is an example of the problems in combining very different compound classes in a correlation with consistent parameters. ${ }^{15 \mathrm{c}, 18 \mathrm{e}}$

To probe this hypothesis, we selected isoquinox ligand L26 (Figure 3 ) as a test compound for a pyrox-type ligand that has a nonzero $\left(46^{\circ}\right)$ dihedral angle in the ground state as a consequence of steric clash between the oxazoline oxygen and the hydrogen at the 8 position of the isoquinoline ring. Indeed, when we measured the disproportionation rate constant of the $[\mathrm{LCo}(\mathrm{I})(\mathrm{MeCN}) \mathrm{Cl}]$ complex ligated by $\mathbf{L 2 6}$, the data best matches the trend of the bpy class, demonstrating that the two distinct correlations are not a result of the nature of the $\mathrm{N}, \mathrm{N}$ ligand but rather a difference in geometry between the ground state ligand and the complex. Indeed, the model in Figure $7 \mathrm{~A}$ overestimates the effect of the dihedral angle for $\mathbf{L 2 6}$ since the effect on the partial charge on nitrogen (from disrupting conjugation with the second ring) of further enlarging the dihedral angle from $30^{\circ}$ to $46^{\circ}$ should not be expected to be linear.

To unify the two distinct correlations with $\mathrm{NBO}_{\mathrm{N} 1}$ seen in Figure $7 \mathrm{~B}$, the geometries of the ligands in the optimized complex structures were analyzed by single-point computations and the partial charge of the most electron deficient nitrogen based on NBO was tabulated. Finally, the bipyridine ligand class was normalized to the pyrox class by adding the net partial charge on the pyridine (0.0256) resultant from charge separation by an unsubstituted oxazoline. The univariate correlation of this normalized NBO partial charge with the $\Delta G^{\ddagger}$ of the $[\mathrm{LCo}(\mathrm{I})(\mathrm{MeCN}) \mathrm{Cl}]$ complexes (Figure $7 \mathrm{C}$ ) accounts for the effect of electron-withdrawing groups on the ligand to both the kinetic and the thermodynamic properties of the outer-sphere electron transfer involved in the disproportionation of the chloride complexes.

2.6. Multivariate Correlation Analysis for Bromide Complexes. Knowledge of how the ligand changes the 
kinetics of the disproportionation of $[\mathrm{LCo}(\mathrm{I})(\mathrm{MeCN}) \mathrm{Cl}]$ (and, concomitantly, the thermodynamics for the chloride complexes) enabled us to investigate the expanded bromide data set. A range of parameters were collected from singlepoint computations of the ligands in the geometries from the optimized cobalt complex structures, covering a variety of electronic and steric properties. Additionally, parameters were also obtained from the computed $\mathrm{Co}(\mathrm{I})$ complexes in their tetrahedral, high-spin ground states to compare the effects of the ligand on the metal complex geometry. In modeling the kinetics of the disproportionation event, we were selective for statistical models which could provide mechanistic rationale for the trends observed based on the ligand. From this data set, a multivariate correlation was found between the free energy of activation and a combination of the potential of the Co(II)/ $\mathrm{Co}(\mathrm{I})$ couple, the electron occupancy of the lone pair on the electron-rich ring by $\mathrm{NBO}$ analysis, and the charge separation between the two rings, also based on NBO (Figure 8A). The model was internally validated by leave-one-out $\left(Q^{2}\right)$ and $K$ fold (4-fold) cross-validation. Both scores are acceptable for a well-validated model.

The first term in this model evaluates the thermodynamic feasibility of the oxidation process in a similar vein to that observed for the $\mathrm{Co}(\mathrm{I}) \mathrm{Cl}$ data set. This potential shows a moderate inverse trend with the energy of the LUMO of the ligand (Figure 8B), indicative of a lower energy ligand LUMO inhibiting the oxidation of $[\mathrm{LCo}(\mathrm{I})(\mathrm{MeCN}) \mathrm{Br}]$. Conceptually, this trend is in concert with the stability afforded by electronwithdrawing ligands for the chloride complexes and is suggestive of favorable $\pi$-back bonding. Additionally, a correlation between free energy of activation and the $\mathrm{Co}-$ NCMe bond length in the tetrahedral $[\mathrm{LCo}(\mathrm{I})(\mathrm{MeCN}) \mathrm{Br}]$ complex was observed (Figure $8 \mathrm{C}$ ). This trend is primarily a result of increased $\pi$-back bonding to the ligand, resulting in weakening of the bond to the solvent molecule (with additional effects of $\sigma$-donation, see Supporting Information).

The remaining parameters included in the model encompass the $\sigma$-donation capability of the more electron-rich ring (i.e., the oxazoline ring for the pyrox ligand class). As the electron occupancy in the nitrogen lone pair (N2, from NBO) increases, the nitrogen binds more tightly to cobalt and prevents association of another ligand (vide infra).

The binding ability of $\mathrm{N} 2$ measured by the occupancy of the nitrogen lone pair is corrected by the cross-term with the charge separation across the two rings, the net sum of the partial charges on all of the atoms contained in the electrondeficient ring according to NBO. For example, unsubstituted pyrox $\mathbf{L} 7$ has an electron-deficient pyridine ring with a net positive charge of 0.0256 (Figure $8 \mathrm{D}$ ). Addition of a 5trifluoromethyl group on the pyridine ring withdraws electron density away from the electron-rich oxazoline ring, decreasing the difference in net partial charges between the two rings to 0.0085 .

The cross-term of the N2 lone pair occupancy with the charge separation can be viewed as the electron density in the lone pair of $\mathrm{N} 2$ as a function of the electron density on the second ring. The inverse relationship with the cross-term is indicative of the greater stability afforded by electronically asymmetric pyrox ligands. ${ }^{19}$

2.7. Mechanistic Proposal. The results obtained from the multivariate linear regression allow us to postulate an alternative disproportionation mechanism for the $[\mathrm{LCo}(\mathrm{I})$ $(\mathrm{MeCN}) \mathrm{Br}]$ species in which the electron is transferred via a
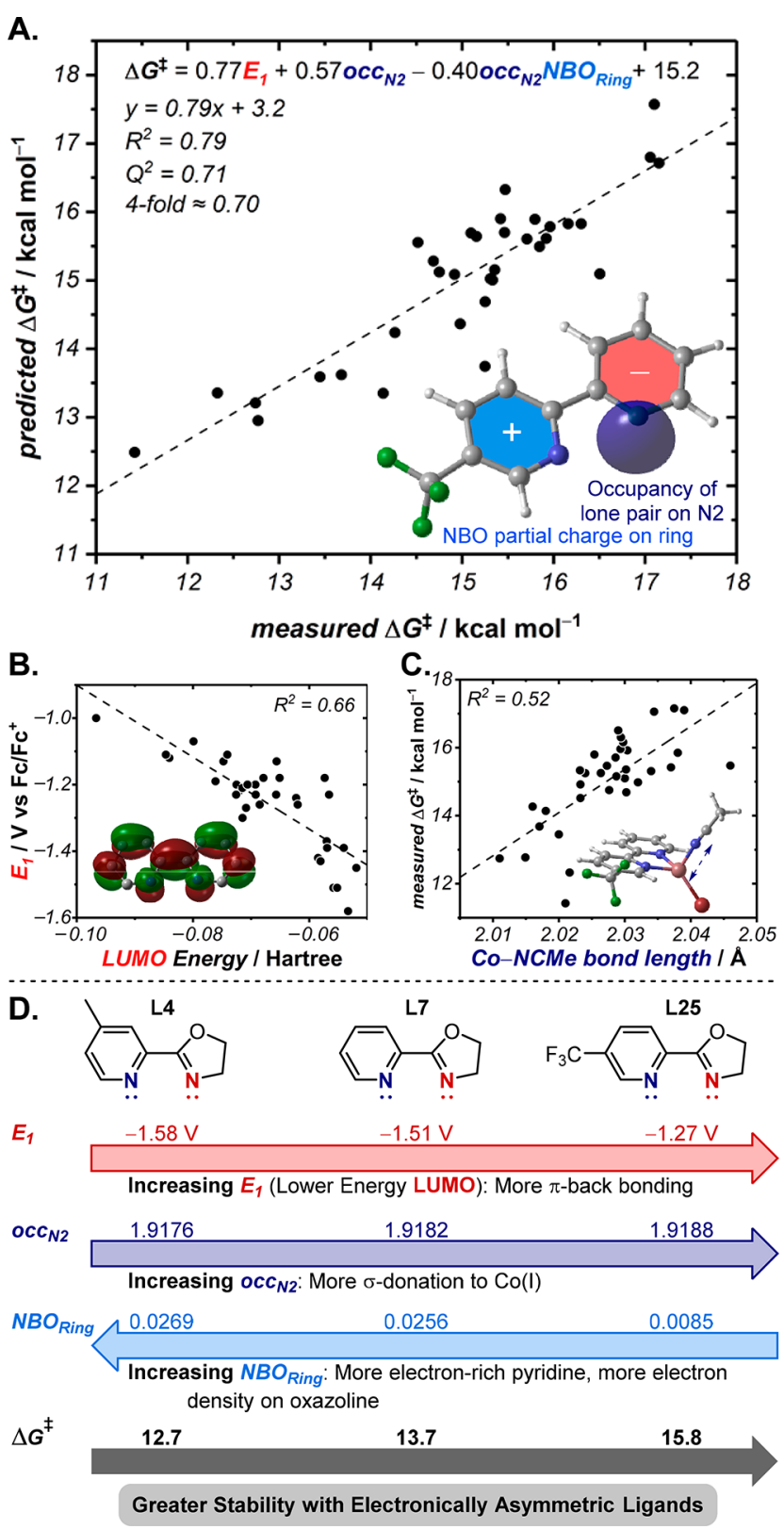

Figure 8. (A) Comprehensive model for the disproportionation of $[\mathrm{LCo}(\mathrm{I})(\mathrm{MeCN}) \mathrm{Br}]$, where $E_{1}$ is the potential of the $\mathrm{Co}(\mathrm{II}) / \mathrm{Co}(\mathrm{I})$ couple, $o c c_{\mathrm{N} 2}$ is the occupancy of the NBO lone pair on the electronrich nitrogen, and $N B O_{\text {Ring }}$ is the sum of the partial charges on all atoms and substituents of the electron-deficient ring. (B) Correlation of the LUMO energy with $\mathrm{Co}(\mathrm{II}) / \mathrm{Co}(\mathrm{I})$ potential. (C) Correlation of cobalt-acetonitrile bond length with the free energy of activation of disproportionation (without three outliers, $R^{2}=0.69$ ). (D) Rationale of the comprehensive model, utilizing a case study of pyrox ligands L4, L7, and L25.

transient $\mu$-bromide-bridged dimer (Figure 9). ${ }^{20}$ This mechanism is consistent with our findings that the complex is stabilized by an electronically asymmetric ligand. The electrondeficient nitrogen removes electron density from the Co(I) metal through $\pi$-back bonding, making oxidation to $\mathrm{Co}$ (II) less thermodynamically feasible (correlation with $E_{1}$, as observed for the chlorides). In contrast, as the second nitrogen becomes sequentially more electron rich, it binds more strongly to the cobalt center (strong $\sigma$-donation from the ligand). This effect electronically stabilizes the $[\mathrm{LCo}(\mathrm{I})(\mathrm{MeCN}) \mathrm{Br}]$ species from 


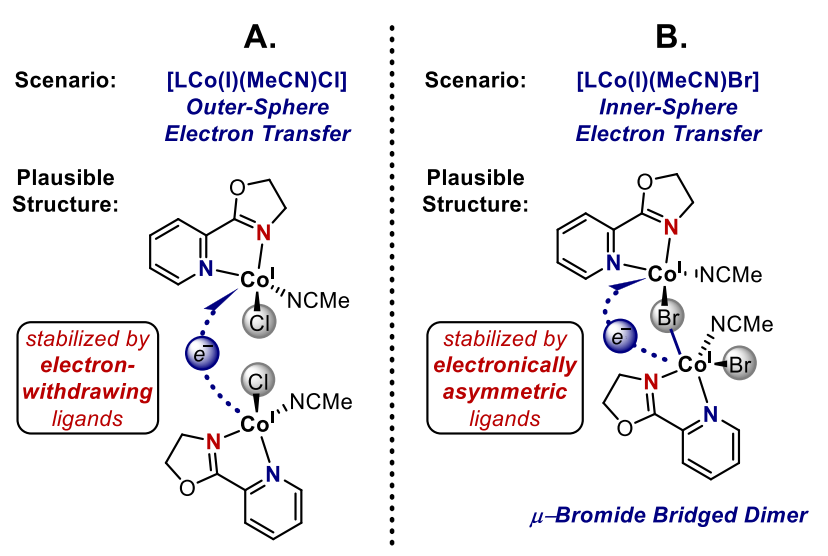

Figure 9. Postulated mechanisms for the electron transfer involved in the disproportionation of $(\mathrm{A})[\mathrm{LCo}(\mathrm{I})(\mathrm{MeCN}) \mathrm{Cl}]$ complexes and (B) $[\mathrm{LCo}(\mathrm{I})(\mathrm{MeCN}) \mathrm{Br}]$ complexes.

undergoing an associative ligand exchange required to transitively form the bridged dimer.

In addition to the statistical model to support our mechanism, upon studying the $[\mathrm{LCo}(\mathrm{I})(\mathrm{MeCN}) \mathrm{I}]$ complexes, we observed multiple reduction couples, the potentials of which were shifted by the addition of further equivalents of ligand (see Supporting Information), which is consistent with shifts observed by the equilibria of dimer formation. ${ }^{21}$ Halides and other anions have been reported to act as bridging ligands in dimeric cobalt species. ${ }^{22}$ Taken together, this provides additional circumstantial evidence in accordance with our postulated dimeric disproportionation mechanism, although an alternative mechanism involving inner-sphere electron transfer cannot be ruled out.

2.8. Rate of Oxidative Addition. In order for these stabilized $\mathrm{Co}(\mathrm{I})$ intermediates to be utilized as electrocatalytic intermediates in cross-coupling and other synthetic applications, they must remain amenable to oxidative addition into a carbon-halide bond. Specifically, the rate of oxidative addition must outcompete the rate of disproportionation. To investigate this we selected benzyl bromide as a model electrophile and measured the cyclic voltammogram of the $\mathrm{Co}(\mathrm{II}) / \mathrm{Co}(\mathrm{I})$ couple with increasing equivalents of benzyl bromide. The addition of $\mathrm{BnBr}$ to $\mathrm{Co}(\mathrm{I})$ complexes of $\mathbf{L 1}$ results in a multifold increase in peak current even as the concentration of $\mathrm{BnBr}$ was increased to 100 -fold excess relative to the bulk cobalt concentration. This behavior along with a shift in the onset of reductive current and the lack of a corresponding oxidation peak is consistent with an electrocatalytic mechanism $\left(E C^{\prime}\right)$. This generally suggests that electrochemically generated $\mathrm{Co}(\mathrm{I})$ reacts with $\mathrm{BnBr}$ to chemically regenerate the original Co(II) complex (Figure 10A). ${ }^{23}$ This observation is in agreement with existing literature, suggesting a stepwise electron transfer from $\mathrm{Co}(\mathrm{I})$ to $\mathrm{BnBr}$ resulting in the formation of transient alkyl radical species in solution. 6 f $12 \mathrm{~b}$

In contrast, for the most stable $[\mathrm{LCo}(\mathrm{I})(\mathrm{MeCN}) \mathrm{Br}]$ complex with L34, the addition of only 1 equiv of $\mathrm{BnBr}$ resulted in a completely irreversible $\mathrm{Co}(\mathrm{II}) / \mathrm{Co}(\mathrm{I})$ couple with a scan rate of $100 \mathrm{mV} \mathrm{s}^{-1}$, owing to rapid oxidative addition completely consuming the $\mathrm{Co}(\mathrm{I})$ intermediate before the reverse scan. In this case, the peak cathodic current does not increase as a function of the concentration of $\mathrm{BnBr}$ (Figure 10B), implying that $\mathrm{Co}(\mathrm{II})$ is not regenerated following the chemical reaction. This is consistent with an EC mechanism in
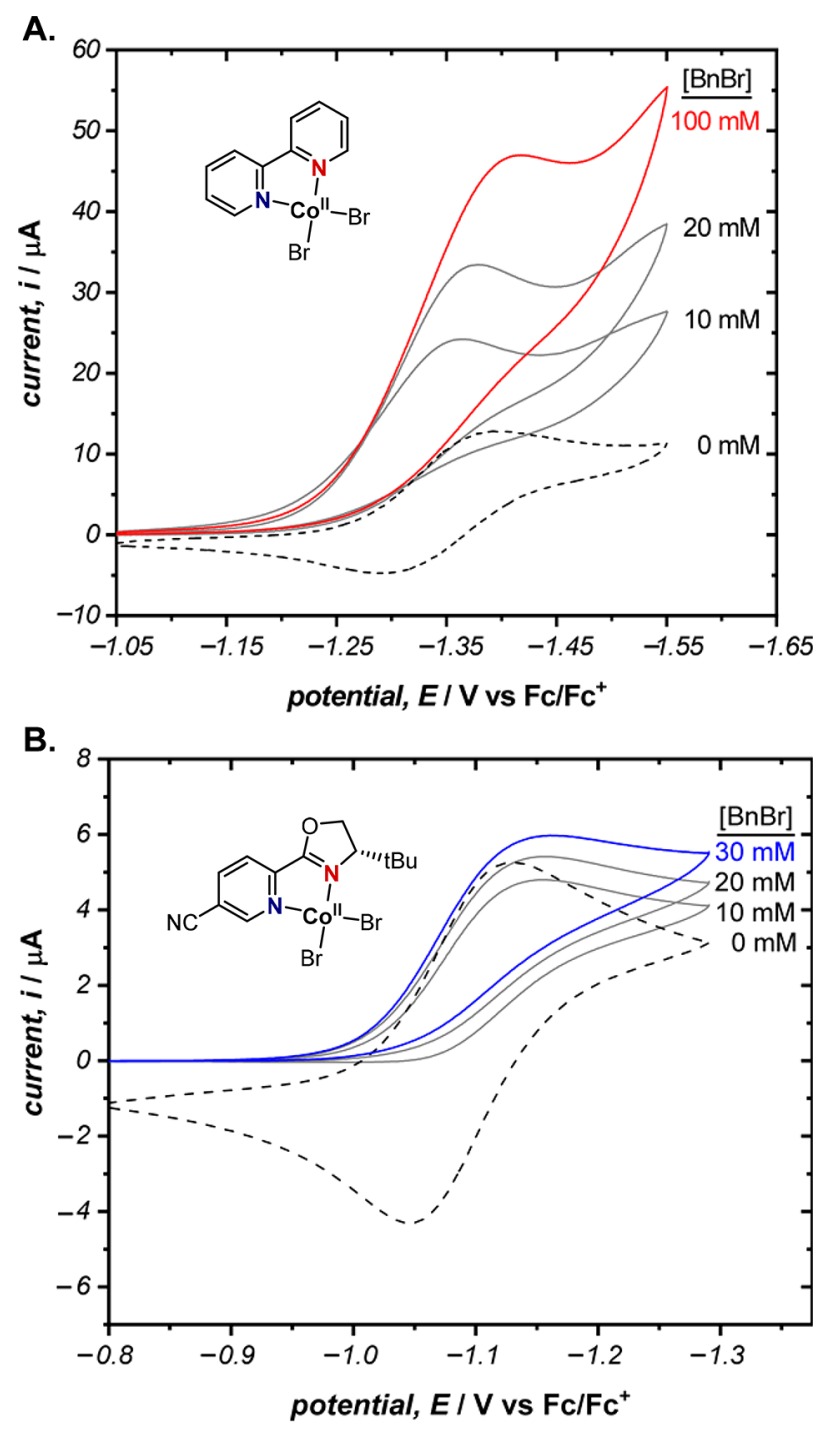

Figure 10. Cyclic voltammogram of the $\mathrm{Co}(\mathrm{II}) / \mathrm{Co}(\mathrm{I})$ couple of $\mathrm{CoBr}_{2}$ ligated by (A) $\mathbf{L} \mathbf{1}$ or (B) $\mathbf{L} 34$ in the presence of increasing equivalents of $\mathrm{BnBr}$. Experiments conducted with $1.0 \mathrm{mM} \mathrm{CoBr}_{2}$ in the presence of $1.0 \mathrm{mM} \mathrm{L1}$ or $\mathbf{L 3 4}$ at $100 \mathrm{mV} \mathrm{s}^{-1}$ in a $100 \mathrm{mM}$ solution of $\mathrm{Bu}_{4} \mathrm{NPF}_{6}$ in acetonitrile. CVs are plotted in polarographic notation with positive currents corresponding to reduction.

which oxidative addition affords a $\mathrm{Co}$ (III) $-\mathrm{C}$ bond. By varying the scan rate of the $\mathrm{CV}$, the measured oxidative addition rate constant $\left(k_{\mathrm{OA}}=7430 \mathrm{dm}^{3} \mathrm{~mol}^{-1} \mathrm{~s}^{-1}\right)$ was found to be over 3 orders of magnitude greater than the disproportionation rate constant $\left(k_{\text {disprop }}=1.63 \mathrm{dm}^{3} \mathrm{~mol}^{-1} \mathrm{~s}^{-1}\right)$ for the same complex. In combination, these results are promising for evaluating future downstream catalytic processes.

\section{CONCLUSIONS}

In conclusion, we have demonstrated the varying effects of ligand properties on the disproportionation of $\mathrm{Co}(\mathrm{I}) \mathrm{X}$ complexes. Electrochemical studies were conducted to rapidly assimilate both kinetic and thermodynamic properties of the complexes. For the chloride complexes, these experimentally derived properties were found to correlate well, and a univariate correlation between the free energy of activation for the disproportionation event with the partial charge of the most electron-deficient nitrogen based on NBO was obtained. 
This is consistent with an outer-sphere electron transfer, with electron-deficient ligands removing electron density from cobalt and stabilizing the complex. In contrast, the bromide complexes were determined to undergo an alternative mechanism for disproportionation, consistent with electronic differentiation of the two nitrogen donors disfavoring electron transfer. With these insights into the conflicting disproportionation mechanisms of coordination complexes, we believe a greater understanding of electron transfer processes in a range of electrocatalysts can be formulated.

Across the range of $N, N$-ligands studied, a $\mathrm{Co}(\mathrm{I})$ complex with pyrox ligand L34 was identified with a half-life $>100$ times greater than that for 2,2'-bipyridine. Additionally, this complex was found to undergo facile oxidative addition with benzyl bromide at a significantly greater rate than deleterious disproportionation. Consequently, this complex poses considerable promise for the development of novel electrocatalytic reactions utilizing cobalt organometallic species.

\section{ASSOCIATED CONTENT}

\section{S Supporting Information}

The Supporting Information is available free of charge on the ACS Publications website at DOI: 10.1021 jacs.8b12634.

Materials and methods, cyclic and square wave voltammograms of complexes, parameters used in the modeling, additional models and correlations, experimental procedures and characterization data for the synthesis of ligands, and coordinates of DFT-optimized ligands and $\mathrm{Co}(\mathrm{I})$ complexes $(\mathrm{PDF})$

\section{AUTHOR INFORMATION}

\section{Corresponding Authors}

*sigman@chem.utah.edu

*minteer@chem.utah.edu

ORCID $\odot$

David P. Hickey: 0000-0002-5297-6895

Christopher Sandford: 0000-0002-4015-0674

Matthew S. Sigman: 0000-0002-5746-8830

Shelley D. Minteer: 0000-0002-5788-2249

\section{Author Contributions}

${ }^{\dagger}$ D.P.H. and C.S. contributed equally.

\section{Notes}

The authors declare no competing financial interest.

\section{ACKNOWLEDGMENTS}

The authors would like to thank the National Science Foundation Center for Synthetic Organic Electrosynthesis for funding (CHE-1740656). C.S. thanks the EU for Horizon 2020 Marie Skłodowska-Curie Fellowship (grant no. 789399), and T.G. thanks the Leopoldina Fellowship Programme of the German National Academy of Sciences Leopoldina (LPDS 2017-18). The support and resources from the Center for High Performance Computing at the University of Utah are gratefully acknowledged.

\section{REFERENCES}

(1) (a) Lexa, D.; Savéant, J. M. The electrochemistry of vitamin B12. Acc. Chem. Res. 1983, 16, 235-243. (b) Scheffold, R.; Abrecht, S.; Orlinski, R.; Ruf, H. R.; Stamouli, P.; Tinembart, O.; Walder, L.; Weymuth, C. Vitamin B12-mediated electrochemical reactions in the synthesis of natural products. Pure Appl. Chem. 1987, 59, 363. (c) Dempsey, J. L.; Brunschwig, B. S.; Winkler, J. R.; Gray, H. B. Hydrogen Evolution Catalyzed by Cobaloximes. Acc. Chem. Res. 2009, 42, 1995-2004. (d) Giedyk, M.; Goliszewska, K.; Gryko, D. Vitamin B12 catalysed reactions. Chem. Soc. Rev. 2015, 44, 3391-3404. (e) Artero, V.; Chavarot-Kerlidou, M.; Fontecave, M. Splitting Water with Cobalt. Angew. Chem., Int. Ed. 2011, 50, 7238-7266. (f) Wang, Y.-H.; Pegis, M. L.; Mayer, J. M.; Stahl, S. S. Molecular Cobalt Catalysts for $\mathrm{O}_{2}$ Reduction: Low-Overpotential Production of $\mathrm{H}_{2} \mathrm{O}_{2}$ and Comparison with Iron-Based Catalysts. J. Am. Chem. Soc. 2017, 139, 16458-16461. (g) Sauermann, N.; Meyer, T. H.; Ackermann, L. Electrochemical Cobalt-Catalyzed $\mathrm{C}-\mathrm{H}$ Activation. Chem. - Eur. J. 2018, 24, 16209-16217.

(2) (a) Hu, X.; Cossairt, B. M.; Brunschwig, B. S.; Lewis, N. S.; Peters, J. C. Electrocatalytic hydrogen evolution by cobalt difluoroboryl-diglyoximate complexes. Chem. Commun. 2005, 47234725. (b) Razavet, M.; Artero, V.; Fontecave, M. Proton Electroreduction Catalyzed by Cobaloximes: Functional Models for Hydrogenases. Inorg. Chem. 2005, 44, 4786-4795. (c) Jacques, P.-A.; Artero, V.; Pécaut, J.; Fontecave, M. Cobalt and nickel diiminedioxime complexes as molecular electrocatalysts for hydrogen evolution with low overvoltages. Proc. Natl. Acad. Sci. U. S. A. 2009, 106, 20627-20632. (d) Dempsey, J. L.; Winkler, J. R.; Gray, H. B. Kinetics of Electron Transfer Reactions of $\mathrm{H}_{2}$-Evolving Cobalt Diglyoxime Catalysts. J. Am. Chem. Soc. 2010, 132, 1060-1065. (e) Solis, B. H.; Hammes-Schiffer, S. Substituent Effects on Cobalt Diglyoxime Catalysts for Hydrogen Evolution. J. Am. Chem. Soc. 2011, 133, 19036-19039. (f) McCrory, C. C. L.; Uyeda, C.; Peters, J. C. Electrocatalytic Hydrogen Evolution in Acidic Water with Molecular Cobalt Tetraazamacrocycles. J. Am. Chem. Soc. 2012, 134, 31643170. (g) Lacy, D. C.; Roberts, G. M.; Peters, J. C. The Cobalt Hydride that Never Was: Revisiting Schrauzer's "Hydridocobaloxime”. J. Am. Chem. Soc. 2015, 137, 4860-4864. (h) Wiedner, E. S.; Bullock, R. M. Electrochemical Detection of Transient Cobalt Hydride Intermediates of Electrocatalytic Hydrogen Production. J. Am. Chem. Soc. 2016, 138, 8309-8318. (i) Lawrence, M. A. W.; Holder, A. A. Assessing the stability of the Co(I) species of two mononuclear dichlorocobalt compounds bearing $2,2^{\prime}$-bipyridine and trans-2-(2'-quiolyl)methylene-3-quinuclidione via ${ }^{59} \mathrm{Co}$ NMR spectroscopy, electrochemical, and catalyzed proton electroreduction studies. Inorg. Chim. Acta 2016, 441, 157-168.

(3) For reviews of cobalt catalyzed $\mathrm{C}-\mathrm{H}$ activations, see: (a) Gao, K.; Yoshikai, N. Low-Valent Cobalt Catalysis: New Opportunities for C-H Functionalization. Acc. Chem. Res. 2014, 47, 1208-1219. (b) Moselage, M.; Li, J.; Ackermann, L. Cobalt-Catalyzed C-H Activation. ACS Catal. 2016, 6, 498-525. (c) Ma, C.; Fang, P.; Mei, T.-S. Recent Advances in $\mathrm{C}-\mathrm{H}$ Functionalization Using Electrochemical Transition Metal Catalysis. ACS Catal. 2018, 8, 7179-7189. For selected examples, see: (d) Zheng, Y.-W.; Ye, P.; Chen, B.; Meng, Q.-Y.; Feng, K.; Wang, W.; Wu, L.-Z.; Tung, C.-H. Benzene C-H Etherification via Photocatalytic Hydrogen-Evolution Cross-Coupling Reaction. Org. Lett. 2017, 19, 2206-2209. (e) Sauermann, N.; Meyer, T. H.; Tian, C.; Ackermann, L. Electrochemical Cobalt-Catalyzed CH Oxygenation at Room Temperature. J. Am. Chem. Soc. 2017, 139, 18452-18455. (f) Tian, C.; Massignan, L.; Meyer, T. H.; Ackermann, L. Electrochemical $\mathrm{C}-\mathrm{H} / \mathrm{N}-\mathrm{H}$ Activation by Water-Tolerant Cobalt Catalysis at Room Temperature. Angew. Chem., Int. Ed. 2018, 57, 2383-2387. (g) Tang, S.; Wang, D.; Liu, Y.; Zeng, L.; Lei, A. Cobaltcatalyzed electrooxidative $\mathrm{C}-\mathrm{H} / \mathrm{N}-\mathrm{H}[4+2]$ annulation with ethylene or ethyne. Nat. Commun. 2018, 9, 798

(4) (a) Gomes, P.; Gosmini, C.; Nédélec, J.-Y.; Périchon, J. Cobalt bromide as catalyst in electrochemical addition of aryl halides onto activated olefins. Tetrahedron Lett. 2000, 41, 3385-3388. (b) Fillon, H.; Le Gall, E.; Gosmini, C.; Périchon, J. Pure acetonitrile as solvent for the efficient electrochemical conversion of aryl bromides in organozinc species and their coupling reaction with acetyl chloride. Tetrahedron Lett. 2002, 43, 5941-5944. (c) Ackerman, L. K. G.; Anka-Lufford, L. L.; Naodovic, M.; Weix, D. J. Cobalt co-catalysis for cross-electrophile coupling: diarylmethanes from benzyl mesylates and aryl halides. Chem. Sci. 2015, 6, 1115-1119. (d) Komeyama, K.; 
Ohata, R.; Kiguchi, S.; Osaka, I. Highly nucleophilic vitamin B12assisted nickel-catalysed reductive coupling of aryl halides and nonactivated alkyl tosylates. Chem. Commun. 2017, 53, 6401-6404. (e) Shevick, S. L.; Obradors, C.; Shenvi, R. A. Mechanistic Interrogation of $\mathrm{Co} / \mathrm{Ni}$-Dual Catalyzed Hydroarylation. J. Am. Chem. Soc. 2018, 140, 12056-12068.

(5) Hicks, J.; Jones, C. Low-Coordinate Cobalt(I) Complexes Stabilized by an Extremely Bulky Amide Ligand. Organometallics 2015, 34, 2118-2121.

(6) (a) Buriez, O.; Cannes, C.; Nédélec, J.-Y.; Périchon, J. Electrogeneration of cobalt(I) species stabilized by pyridine and its reaction with aryl halides. J. Electroanal. Chem. 2000, 495, 57-61. (b) Buriez, O.; Nédélec, J.-Y.; Périchon, J. Stability and reactivity of electrogenerated cobalt(I) towards aryl halides in the presence of additives such as vinyl acetate or methyl vinyl ketone: Application to the electrosynthesis of arylzinc compounds. J. Electroanal. Chem. 2001, 506, 162-169. (c) Polleux, L.; Labbé, E.; Buriez, O.; Périchon, J. $\mathrm{Co}^{\mathrm{I}}$ - and $\mathrm{Co}^{0}-$ Bipyridine Complexes Obtained by Reduction of $\mathrm{CoBr}_{2}$ bpy: Electrochemical Behaviour and Investigation of Their Reactions with Aromatic Halides and Vinylic Acetates. Chem. - Eur. J. 2005, 11, 4678-4686. (d) Buriez, O.; Labbé, E.; Périchon, J. Unexpected stabilization of a simple cobalt(I) salt in acetonitrile at a glassy carbon electrode. J. Electroanal. Chem. 2006, 593, 99-104. See also: (e) Margel, S.; Anson, F. C. Catalysis of the Electroreduction of Allyl Chloride by Cobalt 2,2'-Bipyridine Complexes. J. Electrochem. Soc. 1978, 125, 1232-1235. (f) He, W. Y.; Fontmorin, J. M.; Hapiot, P.; Soutrel, I.; Floner, D.; Fourcade, F.; Amrane, A.; Geneste, F. A new bipyridyl cobalt complex for reductive dechlorination of pesticides. Electrochim. Acta 2016, 207, 313-320.

(7) (a) Masood, A.; Zacharias, P. S. Steric effects and geometrical distortions on a new series of cobalt(II) entwined complexes: stabilization of low valent oxidation states, cobalt(I) and cobalt $(0)$ complex species. Polyhedron 1991, 10, 811-818. (b) Zhou, D.-L.; Gao, J.; Rusling, J. F. Kinetic Control of Reactions of Electrogenerated Co(I) Macrocycles with Alkyl Bromides in a Bicontinuous Microemulsion. J. Am. Chem. Soc. 1995, 117, 1127-1134. (c) Dugan, T. R.; Sun, X.; Rybak-Akimova, E. V.; Olatunji-Ojo, O.; Cundari, T. R.; Holland, P. L. A Masked Two-Coordinate Cobalt(I) Complex That Activates C-F Bonds. J. Am. Chem. Soc. 2011, 133, 12418-12421. (d) Moyses Araujo, C.; Doherty, M. D.; Konezny, S. J.; Luca, O. R.; Usyatinsky, A.; Grade, H.; Lobkovsky, E.; Soloveichik, G. L.; Crabtree, R. H.; Batista, V. S. Tuning redox potentials of bis(imino)pyridine cobalt complexes: an experimental and theoretical study involving solvent and ligand effects. Dalton Trans. 2012, 41, 3562-3573. (e) Waldie, K. M.; Ramakrishnan, S.; Kim, S.-K.; Maclaren, J. K.; Chidsey, C. E. D.; Waymouth, R. M. Multielectron Transfer at Cobalt: Influence of the Phenylazopyridine Ligand. J. Am. Chem. Soc. 2017, 139, 4540-4550. (f) Koide, T.; Aritome, I.; Saeki, T.; Morita, Y.; Shiota, Y.; Yoshizawa, K.; Shimakoshi, H.; Hisaeda, Y. Cobalt-Carbon Bond Formation Reaction via Ligand Reduction of Porphycene-Cobalt(II) Complex and Its Noninnocent Reactivity. ACS Omega 2018, 3, 4027-4034.

(8) (a) Scheffold, R.; Dike, M.; Dike, S.; Herold, T.; Walder, L. Synthesis and reactions of porphine-type metal complexes. 8. Carboncarbon bond formation catalyzed by vitamin B12 and a vitamin B12 model compound. Electrosynthesis of bicyclic ketones by 1,4 addition. J. Am. Chem. Soc. 1980, 102, 3642-3644. (b) Torii, S.; Inokuchi, T.; Yukawa, T. Indirect electrochemical radical cyclization of bromo acetals by cobaloxime(I) as an electron-transfer catalyst. J. Org. Chem. 1985, 50, 5875-5877. (c) Bhandal, H.; Pattenden, G.; Russell, J. J. Oxidative free-radical cyclisations via cobalt (I) reagents. Novel approach to functionalised butyrolactones. Tetrahedron Lett. 1986, 27, 2299-2302. (d) Branchaud, B. P.; Detlefsen, W. D. Cobaloxime-catalyzed radical alkyl-styryl cross couplings. Tetrahedron Lett. 1991, 32, 6273-6276. (e) Giese, B.; Erdmann, P.; Göbel, T.; Springer, R. Cobalt-catalyzed carbon-carbon bond formation via radicals. Tetrahedron Lett. 1992, 33, 4545-4548.

(9) (a) Folest, J.-C.; Duprilot, J.-M.; Périchon, J.; Robin, Y.; Devynck, J. Electrocatalyzed carboxylation of organic halides by a cobalt-salen complex. Tetrahedron Lett. 1985, 26, 2633-2636. (b) Fry, A. J.; Sirisoma, U. N.; Lee, A. S. Conversion of benzal chloride to stilbene by electrogenerated cobalt(I)(salen) a doubly electrocatalytic process. Tetrahedron Lett. 1993, 34, 809-812. (c) Fry, A. J.; Sirisoma, U. N. Electrocatalytic reduction of benzal chloride by cobalt(I)(salen). A mechanistic investigation. J. Org. Chem. 1993, 58, 4919-4924. (d) Kochem, A.; Thomas, F.; Jarjayes, O.; Gellon, G.; Philouze, C.; Weyhermüller, T.; Neese, F.; van Gastel, M. Structural and Spectroscopic Investigation of an Anilinosalen Cobalt Complex with Relevance to Hydrogen Production. Inorg. Chem. 2013, 52, $14428-14438$.

(10) Costentin, C.; Passard, G.; Robert, M.; Savéant, J.-M. Concertedness in proton-coupled electron transfer cleavages of carbon-metal bonds illustrated by the reduction of an alkyl cobalt porphyrin. Chem. Sci. 2013, 4, 819-823.

(11) (a) Ng, F. T. T.; Rempel, G. L.; Mancuso, C.; Halpern, J. Decomposition of ( $\alpha$-phenethyl)bis(dimethylglyoximato)cobalt(III) complexes. Influence of electronic and steric factors on the kinetics and thermodynamics of cobalt-carbon bond dissociation. Organometallics 1990, 9, 2762-2772. (b) Birke, R. L.; Huang, Q.; Spataru, T.; Gosser, D. K. Electroreduction of a Series of Alkylcobalamins: Mechanism of Stepwise Reductive Cleavage of the Co-C Bond. J. Am. Chem. Soc. 2006, 128, 1922-1936. (c) Movassaghi, M.; Schmidt, M. A. Concise Total Synthesis of (-)-Calycanthine, (+)-Chimonanthine, and (+)-Folicanthine. Angew. Chem., Int. Ed. 2007, 46, 37253728. (d) Weiss, M. E.; Kreis, L. M.; Lauber, A.; Carreira, E. M. Cobalt-Catalyzed Coupling of Alkyl Iodides with Alkenes: Deprotonation of Hydridocobalt Enables Turnover. Angew. Chem., Int. Ed. 2011, 50, 11125-11128.

(12) (a) Wakabayashi, K.; Yorimitsu, H.; Oshima, K. CobaltCatalyzed Tandem Radical Cyclization and Cross-Coupling Reaction: Its Application to Benzyl-Substituted Heterocycles. J. Am. Chem. Soc. 2001, 123, 5374-5375. (b) Affo, W.; Ohmiya, H.; Fujioka, T.; Ikeda, Y.; Nakamura, T.; Yorimitsu, H.; Oshima, K.; Imamura, Y.; Mizuta, T.; Miyoshi, K. Cobalt-Catalyzed TrimethylsilylmethylmagnesiumPromoted Radical Alkenylation of Alkyl Halides: A Complement to the Heck Reaction. J. Am. Chem. Soc. 2006, 128, 8068-8077.

(13) Pellissier, H.; Clavier, H. Enantioselective Cobalt-Catalyzed Transformations. Chem. Rev. 2014, 114, 2775-2823.

(14) Guo, J.; Liu, H.; Bi, J.; Zhang, C.; Zhang, H.; Bai, C.; Hu, Y.; Zhang, $\mathrm{X}$. Pyridine-oxazoline and quinoline-oxazoline ligated cobalt complexes: Synthesis, characterization, and 1,3-butadiene polymerization behaviors. Inorg. Chim. Acta 2015, 435, 305-312.

(15) For reviews on pyrox ligands, see: (a) McManus, H. A.; Guiry, P. J. Recent Developments in the Application of OxazolineContaining Ligands in Asymmetric Catalysis. Chem. Rev. 2004, 104, 4151-4202. (b) Yang, G.; Zhang, W. Renaissance of pyridineoxazolines as chiral ligands for asymmetric catalysis. Chem. Soc. Rev. 2018, 47, 1783-1810. For an example of how sterics in pyrox ligands affects catalytic outcomes, see: (c) Guo, J.-Y.; Minko, Y.; Santiago, C. B.; Sigman, M. S. Developing Comprehensive Computational Parameter Sets To Describe the Performance of Pyridine-Oxazoline and Related Ligands. ACS Catal. 2017, 7, 4144-4151.

(16) Evans, D. H.; Lehmann, M. W.; Burghart, A.; Little, D.; Silvestri, G.; Tallec, A.; Shono, T.; Toftlund, H. Two-Electron Reactions in Organic and Organometallic Electrochemistry. Acta Chem. Scand. 1999, 53, 765-774.

(17) Rosokha, S. V.; Kochi, J. K. Fresh Look at Electron-Transfer Mechanisms via the Donor/Acceptor Bindings in the Critical Encounter Complex. Acc. Chem. Res. 2008, 41, 641-653.

(18) For reviews, see: (a) Sigman, M. S.; Harper, K. C.; Bess, E. N.; Milo, A. The Development of Multidimensional Analysis Tools for Asymmetric Catalysis and Beyond. Acc. Chem. Res. 2016, 49, 12921301. (b) Santiago, C. B.; Guo, J.-Y.; Sigman, M. S. Predictive and mechanistic multivariate linear regression models for reaction development. Chem. Sci. 2018, 9, 2398-2412. For selected examples, see: (c) Hickey, D. P.; Schiedler, D. A.; Matanovic, I.; Doan, P. V.; Atanassov, P.; Minteer, S. D.; Sigman, M. S. Predicting Electrocatalytic Properties: Modeling Structure-Activity Relationships of 
Nitroxyl Radicals. J. Am. Chem. Soc. 2015, 137, 16179-16186.

(d) Sevov, C. S.; Hickey, D. P.; Cook, M. E.; Robinson, S. G.; Barnett, S.; Minteer, S. D.; Sigman, M. S.; Sanford, M. S. Physical Organic Approach to Persistent, Cyclable, Low-Potential Electrolytes for Flow Battery Applications. J. Am. Chem. Soc. 2017, 139, 2924-2927. (e) Thornbury, R. T.; Saini, V.; Fernandes, T. de A.; Santiago, C. B.; Talbot, E. P. A.; Sigman, M. S.; McKenna, J. M.; Toste, F. D. The development and mechanistic investigation of a palladium-catalyzed 1,3-arylfluorination of chromenes. Chem. Sci. 2017, 8, 2890-2897.

(19) The term "electronically asymmetric ligands" is used in the context of possessing one electron-deficient and one electron-rich donor. In comparison with the charge separation term $\left(\mathrm{NBO}_{\text {Ring }}\right)$, the pyrox ligands become more electronically asymmetric as the $\mathrm{NBO}_{\text {Ring }}$ decreases with the addition of electron-withdrawing groups on the pyridine ring. For examples of pyrox ligands utilized as electronically asymmetric ligands, see: (a) McDonald, R. I.; White, P. B.; Weinstein, A. B.; Tam, C. P.; Stahl, S. S. Enantioselective Pd(II)-Catalyzed Aerobic Oxidative Amidation of Alkenes and Insights into the Role of Electronic Asymmetry in Pyridine-Oxazoline Ligands. Org. Lett. 2011, 13, 2830-2833. (b) Michel, B. W.; Steffens, L. D.; Sigman, M. S. On the Mechanism of the Palladium-Catalyzed tert-ButylhydroperoxideMediated Wacker-Type Oxidation of Alkenes Using Quinoline-2Oxazoline Ligands. J. Am. Chem. Soc. 2011, 133, 8317-8325.

(20) (a) Miyamoto, K.; Takano, K.; Fukuda, Y. Theoretical Study on the Disproportionation Reaction of Nickel(II) Mixed-Ligand Complexes Containing $N, N, N^{\prime}, N^{\prime}$-Tetramethylethylenediamine, Benzoylacetonate, and a Halide Anion. Bull. Chem. Soc. Jpn. 2005, 78, 2124-2129. (b) Barakat, K. A.; Cundari, T. R.; Rabaâ, H.; Omary, M. A. Disproportionation of Gold(II) Complexes. A Density Functional Study of Ligand and Solvent Effects. J. Phys. Chem. B 2006, 110, 14645-14651.

(21) (a) Andrieux, C. P.; Nadjo, L.; Savéant, J. M. Electrodimerization: VII. Electrode and solution electron transfers in the radical-substrate coupling mechanism. discriminative criteria from the other mechanisms in voltammetric studies (Linear sweep, rotating disc, polarography). J. Electroanal. Chem. Interfacial Electrochem. 1973, 42, 223-242. (b) Duplessis, E. A.; Jelliss, P. A.; Kirkpatrick, C. C.; Minteer, S. D.; Wampler, K. M. Electrocatalytic reductive dimerization of the 2,2'-bipyridyl tungsten alkylidyne complex $\left[\mathrm{W}\left(\equiv \mathrm{CC}_{6} \mathrm{H}_{4} \mathrm{NMe}_{2}-4\right)(\mathrm{NCMe})(\mathrm{CO})_{2}\left\{\kappa^{2}-2,2^{\prime}-\left(\mathrm{NC}_{5} \mathrm{H}_{4}\right)_{2}\right\}\right]^{+}$. J. Organomet. Chem. 2006, 691, 4660-4666.

(22) (a) Sumner, C. E.; Steinmetz, G. R. Isolation of oxo-centered cobalt(III) clusters and their role in the cobalt bromide catalyzed autoxidation of aromatic hydrocarbons. J. Am. Chem. Soc. 1985, 107, 6124-6126. (b) Jenkins, D. M.; Di Bilio, A. J.; Allen, M. J.; Betley, T. A.; Peters, J. C. Elucidation of a Low Spin Cobalt(II) System in a Distorted Tetrahedral Geometry. J. Am. Chem. Soc. 2002, 124, 15336-15350.

(23) (a) Savéant, J. M. Cyclic voltammetry with asymmetrical potential scan: A simple approach to mechanisms involving moderately fast chemical reactions. Electrochim. Acta 1967, 12, 999-1030. (b) Andrieux, C. P.; Blocman, C.; Dumas-Bouchiat, J. M.; M'Halla, F.; Savéant, J. M. Homogeneous redox catalysis of electrochemical reactions: Part V. Cyclic voltammetry. J. Electroanal. Chem. Interfacial Electrochem. 1980, 113, 19-40. 